\title{
Ocean mixed layer processes in the Pacific Decadal Oscillation in coupled general circulation models
}

\author{
Bo Young Yim • Yign Noh $\cdot$ Sang-Wook Yeh • \\ Jong-Seong Kug $\cdot$ Hong Sik Min $\cdot$ Bo Qiu
}

Received: 7 June 2012/ Accepted: 10 December 2012/Published online: 29 December 2012

(C) Springer-Verlag Berlin Heidelberg 2012

\begin{abstract}
It is investigated how the Pacific Decadal Oscillation (PDO) is simulated differently among various coupled general circulation models (CGCMs), and how it is related to the heat budget of the simulated ocean mixed layer, which includes the surface heat flux and ocean heat transport. For this purpose the dataset of the climate of the 20th Century experiment (20C3M) from nine CGCMs reported to IPCC's AR4 are used, while the MRI and MIROC models are examined in detail. Detailed analyses of these two CGCMs reveal that the PDO is mainly affected by ocean heat transport rather than surface heat flux, in particular in the MRI model which has a larger contribution of ocean heat transport to the heat budget. It is found that the ocean heat transport due to Ekman advection versus geostrophic advection contributes differently to the PDO in the western and central North Pacific. Specifically, the strength of PDO tends to be larger for CGCMs with a larger ocean heat transport in the region.
\end{abstract}

B. Y. Yim · J.-S. Kug $\cdot$ H. S. Min

Korea Institute of Ocean Science and Technology,

Ansan, South Korea

Y. Noh

Department of Atmospheric Sciences/Global Environmental Laboratory, Yonsei University, Seoul, South Korea

S.-W. Yeh $(\square)$

Department of Environmental Marine Science, Hanyang University, ERICA Campus, Ansan 426-791, South Korea e-mail: swyeh@hanyang.ac.kr

B. Qiu

Department of Oceanography, University of Hawaii at Manoa, Honolulu, HI, USA
Keywords Pacific Decadal Oscillation - El Niño and Southern Oscillation - Coupled general circulation models . Heat budget of the mixed layer

\section{Introduction}

The Pacific Decadal Oscillation (PDO) is the most dominant variability of the North Pacific sea surface temperature (SST) on decadal time scales, and strongly influences the climate and ecosystems surrounding the North Pacific (Mantua et al. 1997; Zhang et al. 1997; Mantua and Hare 2002). Furthermore, the PDO is able to modulate the atmospheric teleconnections from the tropics to the midlatitudes (Gershunov and Barnett 1998; Pavia et al. 2006; Yoon and Yeh 2010). Thus, it is important to examine the PDO mechanism in order to understand climate variability in the extra-tropics.

Many studies have proposed various physical mechanisms responsible for the PDO, including stochastic variations in atmospheric forcing (e.g., Frankignoul and Hasselmann 1977; Frankignoul 1985; Kleeman and Power 1995), atmospheric teleconnections of El Niño and Southern Oscillation (ENSO; e.g., Trenberth 1990; Miller et al. 1994a, b; Zhang et al. 1996), ocean-atmosphere interactions over the North Pacific (e.g., Latif and Barnett 1994, 1996; Qiu et al. 2007), and tropicalextratropical interactions in the ocean (e.g., Capotondi and Alexander 2001; Wu et al. 2003; Yang et al. 2004; see review by Miller and Schneider 2000). Meanwhile, observational studies suggest that the PDO consists of two dominant variability modes; a bi-decadal ENSO mode and a multi-decadal North Pacific mode (Deser and Blackmon 1995; Minobe 1997; Nakamura et al. 1997; Zhang et al. 1997; Enfield and Mestas-Nuñez 1999; Barlow et al. 2001; Schneider and Cornuelle 2005). The bi-decadal ENSO mode is associated with SST variability in the central North Pacific, which is 
remotely forced from the ENSO through the tropic-midlatitude atmospheric teleconnections, and the multi-decadal North Pacific mode is associated with the SST variability in the Kuroshio Extension, which is mainly due to local oceanatmosphere coupling processes (Deser and Blackmon 1995; Nakamura et al. 1997; Zhang et al. 1997; Wu et al. 2003).

In addition to the aforementioned mechanisms, several studies emphasize the critical role of ocean dynamics in the PDO (Pierce et al. 2001; Wu et al. 2003; Qiu et al. 2007). For example, by comparing the coupled general circulation model (CGCM) results with and without ocean dynamics, Pierce et al. (2001) found that ocean dynamics acts to enhance the decadal SST variability in the Kuroshio Extension region. In another study based on heat content budget analysis, Yu and Boer (2004) showed that ocean heat transport in the western North Pacific generates heat content anomalies and they are advected to the equator leading to the PDO phase change. Similarly, Zhang and Yu (2011) analyzed the heat budget of the upper ocean to examine the phase transition in the PDO. They showed that variations in the ocean meridional heat transport including both Ekman and geostrophic advection are directly linked to the decadal SST variability in the Pacific and suggested that heat transport, which is associated with the PDO phase transition, is one of major mechanisms responsible for the decadal variations in the Pacific.

Recently, Yim et al. (2012) investigated the heat budget of the mixed layer in the North Pacific during the boreal winter and found that a large difference exists in the relative contribution of ocean heat transport versus surface heat flux in the heat budget of the mixed layer among the Coupled Model Intercomparison Project phase 3 (CMIP3) multi-model dataset of Intergovernmental Panel on Climate Change (IPCC)'s Fourth Assessment Report (AR4). They suggested that it leads to the significant difference in responses of the SST and the mixed layer depth (MLD) to global warming. Consequently, these differences in the contribution of ocean heat transport may also affect the PDO in terms of its spatial structure and amplitude.
In this paper, we attempt to clarify the relationship between the heat budget of the ocean mixed layer and the characteristics of the projected PDO in CGCMs in order to understand the role of ocean heat transport on the PDO. Our results indicate that there exists a different mechanism on the PDO simulated by each CGCM. Therefore, one should be cautious about interpreting modeling results to understand the PDO mechanism as a proxy for observations.

\section{Models and methodology}

\subsection{Model output}

The CGCMs used in this study are part of the World Climate Research Programme's (WCRP's) CMIP3 multimodel dataset and were performed for the IPCC's AR4. These dataset are provided by the Program for Climate Model Diagnosis and Intercomparison (PCMDI); http:// www-pcmdi.llnl.gov/ipcc/about_ipcc.php (e.g., Meehl et al. 2007). The nine CGCMs used here are listed in Table 1. These models are selected based on the availability of output data necessary to calculate the heat budget of the mixed layer, while outdated model versions are excluded.

The climate of the 20th Century experiment (20C3M) from 1901 to 1999 is used here, which was initialized from a point early enough in the pre-industrial control run fixed at the atmospheric $\mathrm{CO}_{2}$ of $280 \mathrm{ppm}$ level. Accordingly, all of the models used in these simulations implemented external forcing from the anthropogenic emissions of greenhouse gases and sulfate aerosols from the late 19th to the end of the 20th century. For each model, only one member run out of several ensemble members is used. In general, Run1 is used in the CMIP3 dataset; however, Run2 is used for the MIROC model because some of data for the surface heat fluxes is not available in Run1 of the 20C3M experiment.

Table 1 The CGCMs used in this study (referred to by the names given in parentheses)

\begin{tabular}{llll}
\hline Model (acronym) & Resolution & Reference \\
\cline { 2 - 3 } & Atmosphere & Ocean & Yukimoto et al. (2001) \\
\hline MRI-CGCM2.3.2 (MRI) & T42, L30 & $2.5^{\circ}\left(\right.$ Lon.) $\times 0.5^{\circ}-2^{\circ}$ (Lat.), L23 & Delworth et al. (2006) \\
GFDL-CM2.0 (GFDL) & $2.5^{\circ} \times 2^{\circ}, \mathrm{L} 24$ & $1^{\circ} \times 0.3^{\circ}-1^{\circ}, \mathrm{L} 50$ & Flato and Boer (2001) \\
CGCM3.1_T47 (CGCM_T47) & $\mathrm{T} 47, \mathrm{~L} 31$ & $1.9^{\circ} \times 1.9^{\circ}, \mathrm{L} 29$ & Salas-Melia et al. (2005) \\
CNRM-CM3 (CNRM) & $\mathrm{T} 63, \mathrm{~L} 45$ & $2^{\circ} \times 0.5^{\circ}-2^{\circ}, \mathrm{L} 31$ & Legutke and Voss (1999) \\
ECHO-G (ECHO) & $\mathrm{T} 30, \mathrm{~L} 19$ & $2.8^{\circ} \times 0.5^{\circ}-2.8^{\circ}, \mathrm{L} 20$ & Hasumi and Emori (2004) \\
MIROC3.2_medres (MIROC) & $\mathrm{T} 42, \mathrm{~L} 20$ & $1.4^{\circ} \times 0.5^{\circ}-1.4^{\circ}, \mathrm{L} 43$ & Goosse and Fichefet (1999) \\
IPSL-CM4 (IPSL) & $3.75^{\circ} \times 2.5^{\circ}, \mathrm{L} 19$ & $2^{\circ} \times 0.5-2^{\circ}, \mathrm{L} 31$ & Gordon et al. (2000) \\
UKMO-HadCM3 (UKMO) & $3.75^{\circ} \times 2.5^{\circ}, \mathrm{L} 19$ & $1.25^{\circ} \times 1.25^{\circ}, \mathrm{L} 20$ & Marsland et al. (2003) \\
ECHAM5/MPI-OM (ECHAM) & $\mathrm{T} 63, \mathrm{~L} 31$ & $1.5^{\circ} \times 1.5^{\circ}, \mathrm{L} 40$ &
\end{tabular}


All quantities presented in this study are based on monthly data and then averaged over the analysis period to produce climatological values. In addition, we analyze only the winter season from October to February, when the MLD is deepest and the influences of both surface heat flux and ocean heat transport are most prominent and the PDO is strongest. According to previous studies, variability of the winter MLD and heat budget of the mixed layer in the North Pacific on the interannual and decadal time scales is closely related to the PDO (Deser et al. 1996; Qiu and Chen 2006; Dawe and Thompson 2007; Carton et al. 2008; Kang et al. 2010). The MLD is determined by the depth where temperature differs from the SST by $0.5{ }^{\circ} \mathrm{C}$, as in Levitus (1982) and Monterey and Levitus (1997).

\subsection{Statistical techniques}

The PDO is defined as the leading empirical orthogonal function (EOF) of winter mean SST anomaly (SSTA) in the North Pacific $\left(120^{\circ} \mathrm{E}-100^{\circ} \mathrm{W}, 20^{\circ} \mathrm{N}-60^{\circ} \mathrm{N}\right)$ and the PDO index is defined by the first principal component (PC) time series (Mantua et al. 1997). The positive/negative phase of the PDO corresponds to the case in which the PDO index is above/below zero. More specifically, a positive PDO phase corresponds to negative SSTAs in the central and western North Pacific. In this paper, the year 1902 means October 1901-February 1902. In order to compare the strength of the PDO in various CGCMs, the PDO index is normalized by the standard deviation of the first PC and the leading EOF is multiplied by the corresponding value.

For EOF analysis, each field is weighted by the square root of the cosine of latitude before computing the eigenvalues and eigenfunctions of covariance matrix $\boldsymbol{A}$. The anomalous fields are calculated by removing the climatological monthly mean. The anomalies are then linearly detrended over the analysis period, and averaged over the winter season.

\subsection{Heat budget of the mixed layer}

The heat budget of the mixed layer during winter can be represented as (Tomita and Nonaka 2006; Kang et al. 2010)

$$
\begin{aligned}
\int_{0}^{h_{2}}\left[T\left(z, t_{2}\right)-T\left(z, t_{1}\right)\right] d z= & \frac{1}{\rho c_{p}} \int_{t_{1}}^{t_{2}} Q_{0} d t+\int_{0}^{h_{2}} \int_{t_{1}}^{t_{2}} F d t d z \\
& +\int_{t_{1}}^{t_{2}} G\left(z=h_{2}\right) d t .
\end{aligned}
$$

Here $t_{1}$ and $t_{2}$ represent the start and end of winter, respectively, $h_{2}$ is the MLD at $t=t_{2}, \rho$ and $c_{p}$ are the density and heat capacity of sea water, respectively, $Q_{0}$ is the net surface heat flux, $F$ is the horizontal heat flux convergence, and $G$ is the vertical heat flux across $h_{2}$. Penetration of solar radiation can be neglected, since the winter MLD is sufficiently deep. The last term on the righthand side (RHS) of (1) is also usually negligible if MLD is sufficiently deep (Dawe and Thompson 2007). As suggested by Tomita et al. (2002), the horizontal heat flux below the mixed layer must also be included here as long as its depth is shallower than the winter MLD, because it is incorporated into the winter mixed layer ultimately. Hereafter, we refer to the term on the left-hand side (LHS) of (1) that represents the heat content variation as HCV. Likewise, we refer to the first term on the RHS representing the contribution from the surface heat flux as SHF and the combination of the second and third terms on the RHS representing the contribution from the ocean heat transport by advection and diffusion as OHT. Using these terms, (1) can be rewritten as $\mathrm{HCV}=\mathrm{SHF}+\mathrm{OHT}$. It should be mentioned, however, that to represent the real heat flux and heat content variation, the terms must be multiplied by $\rho c_{p}$ in (1).

Moreover, $F$ can be decomposed into advection by the Ekman velocity $\boldsymbol{u}_{\boldsymbol{E}}$ and the geostrophic velocity $\boldsymbol{u}_{\boldsymbol{G}}$, and horizontal diffusion by eddy diffusivity $A_{h}$ as

$F=-\nabla \cdot\left(\mathbf{u}_{\mathrm{E}} T\right)-\nabla \cdot\left(\mathbf{u}_{\mathbf{G}} T\right)+\nabla \cdot\left(A_{h} \nabla T\right)$.

Here the contribution from Ekman advection was calculated by

$\int_{t_{1}}^{t_{2}} \int_{0}^{h_{2}}-\nabla \cdot\left(\mathbf{u}_{\mathrm{E}} T\right) d z d t=\int_{t_{1}}^{t_{2}}-\mathbf{U}_{\mathbf{E}} \cdot \nabla T_{m} d t$.

where $\mathbf{U}_{\mathbf{E}}=\tau \times \mathbf{k} /(\rho f), \tau$ is the surface wind stress, $\mathbf{k}$ is the vertical unit vector, and $T_{m}$ is the mean temperature within the mixed layer (e.g., Tomita et al. 2002). Geostrophic advection was calculated by the total advection minus Ekman advection, while the total advection was calculated directly from the velocity and temperature fields of the output data. We refer to the first and second components of OHT in (2) that represents Ekman advection and geostrophic advection as ADV_E and ADV_G, respectively. The residual term represents mostly the contribution from horizontal eddy diffusion.

In the present work we present detailed analyses of two CGCMs, the MRI and MIROC models, as in Yim et al. (2012). The MRI and MIROC models represent the typical cases for large and small values of OHT in the heat budget of the mixed layer among nine CGCMs, respectively (Table 1). It is also necessary to note that the variability of SST is correlated with that of HCV in the western and central North Pacific at the $90 \%$ confidence level in both CGCMs (not shown). 


\section{Results}

We begin by showing the difference in the dynamical process of the mixed layer during winter simulated by the MRI and MIROC models. Figure 1a-d show the distributions of OHT and SHF averaged over the analysis period [1902-1999] in the two CGCMs. Here OHT is calculated by $\mathrm{HCV}-\mathrm{SHF}$ in (1). ${ }^{1}$ The area with large OHT along the western boundary, which is related to the larger and more diffuse northward velocity in the ocean interior in the MRI model (Yim et al. 2012), and large SHF around the Kuroshio Extension region is broader in the MRI model. In particular, large positive OHT is present in most regions of the North Pacific in the MRI model, whereas it is confined to the western boundary in the MIROC model, with negative OHT in the central North Pacific. It should be mentioned that the small scale structures of the OHT in the western part in the MIROC model result from large changes in ocean temperature within the mixed layer rather than MLD (not shown).

To more thoroughly illustrate the relative importance of OHT versus SHF in the two CGCMs, the ratio of OHT to $\mathrm{SHF}(\mathrm{OHT} / \mathrm{SHF})$ is shown in Fig. 1e, f, respectively. Note that the color of the ratio is marked oppositely to emphasize a sign of OHT (i.e., red color indicates negative ratios). This shows that its magnitude, $R(=\mid \mathrm{OHT} / \mathrm{SHF})$ in the MRI model is larger than in the MIROC model in most regions except near the western boundary. Furthermore, the domain $\left(120^{\circ} \mathrm{E}-100^{\circ} \mathrm{W}, 20^{\circ} \mathrm{N}-60^{\circ} \mathrm{N}\right)$ averaged $R$ is found to be 0.41 and 0.23 in the MRI and MIROC models, respectively. A remarkable resemblance between the ratio and OHT in both CGCMs indicates that the difference in $R$ is mainly affected by OHT rather than SHF. We hypothesize that this difference contributes to the difference in the PDO characteristics in CGCMs, assuming ocean dynamics play an important role in the PDO, as suggested by Pierce et al. (2001).

Figure 2 compares the spatial patterns of the leading EOFs of the North Pacific winter mean SSTAs in the MRI and MIROC models. The 1st EOF explains 34 and $19 \%$ of the total variance in the MRI and MIROC models, respectively. Negative SSTAs in the central and western North Pacific and positive SSTAs in the eastern North Pacific are found in both CGCMs, which are consistent with the results of previous studies (Mantua et al. 1997; Mantua and Hare 2002). However, notable distinctions between the two CGCMs are apparent not only in the PDO pattern but also in its strength. For example, while the large variance of SSTA is observed in the eastern and central

\footnotetext{
$\overline{1}$ Output data of vertical velocity and eddy diffusivity are not available in the CMIP3 dataset, therefore, we obtain the OHT by subtracting the SHF from the HCV.
}

North Pacific in the MRI model, it is centered near $40^{\circ} \mathrm{N}$ and extended zonally from the western and central North Pacific in the MIROC model. The strength of $\mathrm{PDO}^{2}$ in the western North Pacific $\left(140^{\circ} \mathrm{E}-170^{\circ} \mathrm{E}, 35^{\circ} \mathrm{N}-45^{\circ} \mathrm{N}\right.$; WNP) is comparable between the two CGCMs, whereas it in the central North Pacific $\left(170^{\circ} \mathrm{W}-140^{\circ} \mathrm{W}, 30^{\circ} \mathrm{N}-40^{\circ} \mathrm{N}\right.$; CNP) is much larger in the MRI model than in the MIROC model (Table 2).

Previous studies suggested that the SSTA variability in the central North Pacific is principally associated with ENSO variability (Deser and Blackmon 1995; Nakamura et al. 1997; Schneider and Cornuelle 2005). Figure 3a, b display the regressed SSTAs with the normalized NINO3.4 SST index in the MRI model and the MIROC model, respectively. Note that the ENSO amplitude, which is calculated by the standard deviation of the NINO3.4 SST index, is 0.80 and $0.55{ }^{\circ} \mathrm{C}$ in these models, respectively. It is evident that the spatial pattern of regressed SSTAs with the normalized NINO3.4 SST index has some similarities and differences in comparison with the PDO simulated by the two CGCMs (Fig. 2). One can find that the PDO signal in the central North Pacific is closely related to the ENSO, but its sign in the western North Pacific is different from that of SSTAs associated with the ENSO in the MRI model. On the other hand, large negative SSTAs associated with ENSO is observed and confined in the western North Pacific in the MIROC model, indicating that the PDO in the western North Pacific is closely related to the ENSO in comparison with that in the central North Pacific. Thus, these results indicate that together with the tropical forcing (i.e., ENSO), the heat budget of the mixed layer also may contribute to the difference in PDO characteristics in the two CGCMs. Hereafter, we focus on the role of SHF and OHT on the PDO simulated by the two CGCMs.

In order to examine this, we first investigate whether the variability of SHF and OHT in the heat budget of the mixed layer is related to PDO and how its relation differs in the MRI and MIROC models. We compute regression coefficients of SHF and OHT anomalies with the PDO index in the two CGCMs (Fig. 4). One can find that there exists a lack of structure in local correlation between SHF (Fig. 4a, b) and PDO (Fig. 2a, b), in particular, in the MRI model. The spatial pattern of regressed SHF anomalies show large differences to the PDO structure except but the eastern North Pacific along the western coast of USA in the MRI model. Simply put, this result indicates that the SST change associated with the PDO may be due to the change in the ocean circulation rather than in the SHF in the MRI model

\footnotetext{
2 As mentioned on Sect. 2.2, the leading EOF here is multiplied by the standard deviation of the first PC to compare the strength of the PDO in various CGCMs. Thus, the magnitude of the leading EOFs averaged over each region is considered as the strength of the PDO in this study.
} 
(a) OHT: MRI

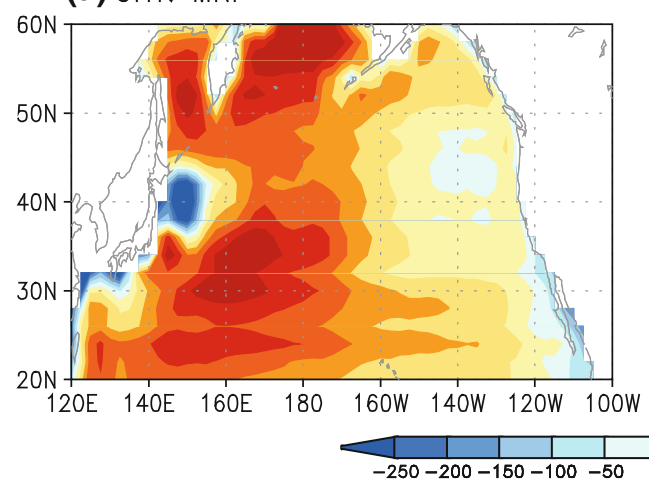

(c) SHF: MRI
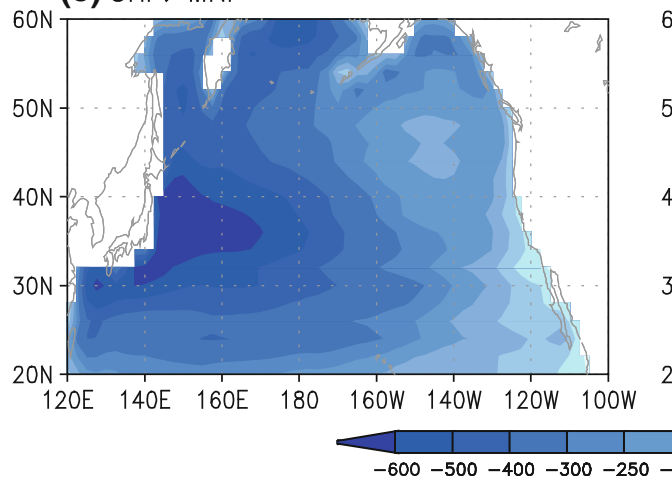

(e) OHT/SHF: MRI

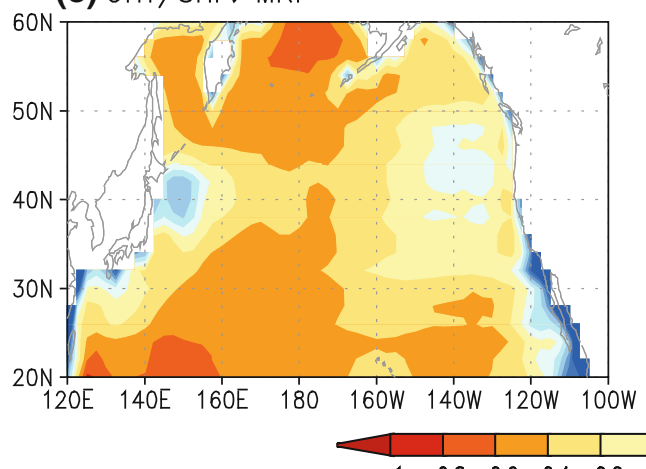

(b) MIROC

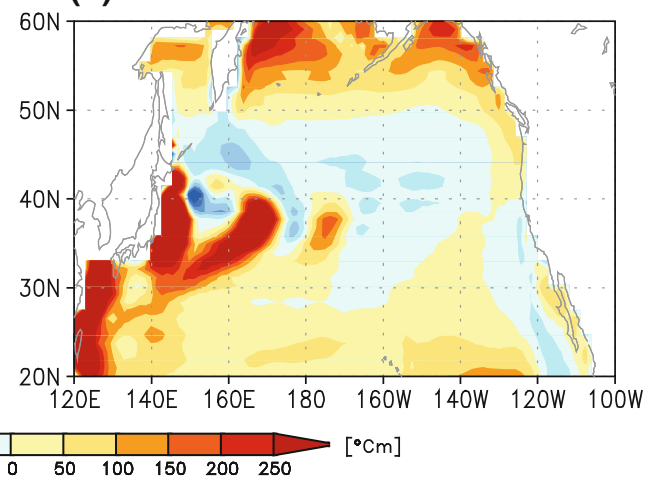

(d) MIROC

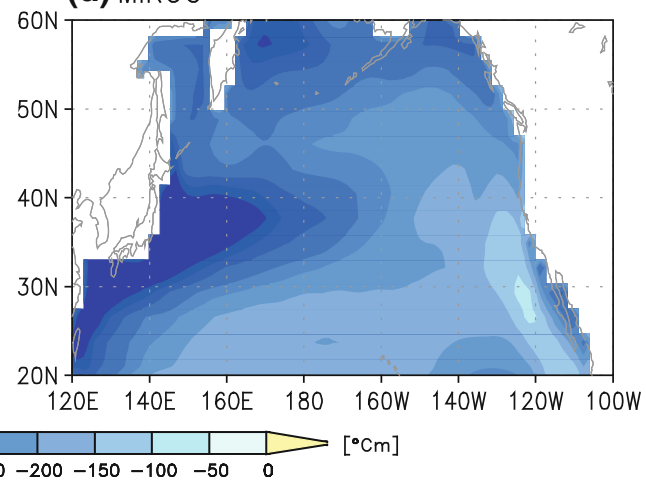

(f) MIROC

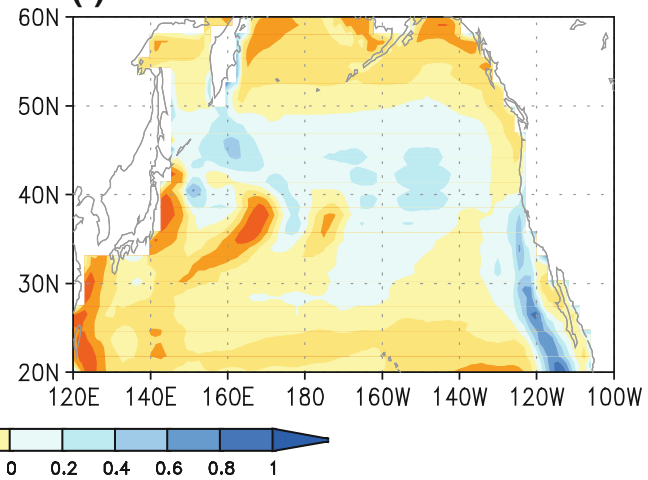

Fig. 1 Distributions of $\mathbf{a}, \mathbf{b}$ OHT, $\mathbf{c}, \mathbf{d}$ SHF, and $\mathbf{e}, \mathbf{f}$ the ratio of OHT to SHF in the MRI and MIROC models. Note that the color scale of the $\mathrm{SHF}$ values in $(\mathbf{c}, \mathbf{d})$ is much larger than that of the OHT values in $(\mathbf{a}, \mathbf{b})$ and the color in $(\mathbf{e}, \mathbf{f})$ is opposite to that in $(\mathbf{a}, \mathbf{b})$

as previous study pointed out (Kang et al. 2010). In contrast, the overall distributions of the enhanced surface cooling in the southwestern North Pacific and weakened surface cooling in the eastern North Pacific are in agreement with the SSTA pattern of a positive PDO phase in the MIROC model although a slight spatial dissimilarity between them exists. Therefore, the SHF plays a role in changing the SST associated with the PDO in some parts of the North Pacific in the MIROC model. In addition, it is noteworthy that we computed the regressed SHF anomalies associated with the variability of the Aleutian Low (not shown). It is found that the spatial structures of regressed SHF anomalies are similar to those with the PDO as shown in Fig. 4a, b except but the magnitude, indicating that change in SHF associated with the PDO is mostly due to the variability of the Aleutian low in both CGCMs.

On the other hand, a remarkable resemblance is found in the regressed OHT anomalies compared with the PDO in both CGCMs (Fig. 4c, d), suggesting that the OHT plays a role in changing the SST associated with the PDO in both CGCMs. In particular, large negative OHT anomalies associated with a positive PDO phase appear in the western and central North Pacific in the MRI model. In comparison 
(a) MRI (34\%)

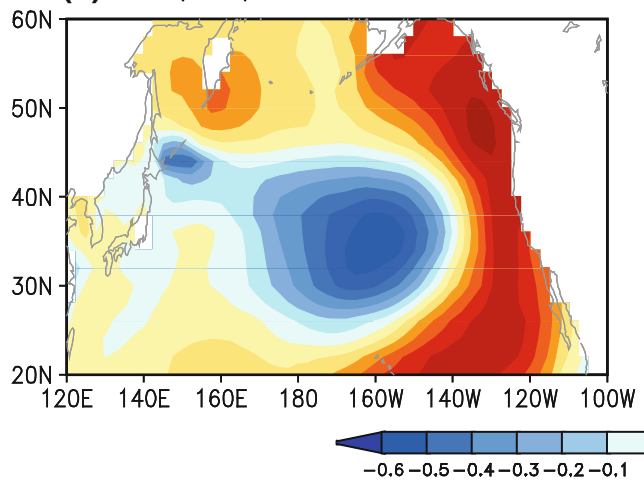

(b) MIROC (19\%)

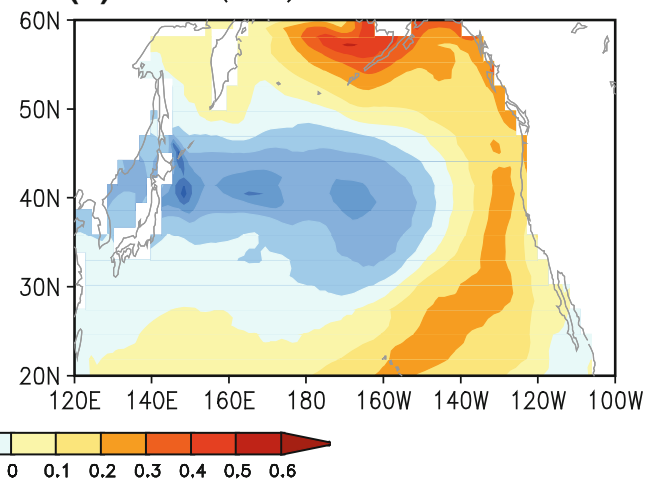

Fig. 2 Spatial patterns of the leading EOFs of the North Pacific winter mean SSTAs in the two CGCMs. The percentage of variance explained is given after the model name

Table 2 The strength of PDO in the western North Pacific $\left(140^{\circ} \mathrm{E}-\right.$ $170^{\circ} \mathrm{E}, 35^{\circ} \mathrm{N}-45^{\circ} \mathrm{N}$; WNP) and central North Pacific $\left(170^{\circ} \mathrm{W}-140^{\circ} \mathrm{W}\right.$, $30^{\circ} \mathrm{N}-40^{\circ} \mathrm{N}$; CNP) in the MRI and MIROC models

\begin{tabular}{lcc}
\hline & WNP & CNP \\
\hline MRI & 0.23 & 0.57 \\
MIROC & 0.25 & 0.13 \\
\hline
\end{tabular}

with Fig. 4a, b, therefore, we suggest that both SHF and OHT act to change the SST associated with the PDO in the MIROC model, in contrast, the OHT plays a key role in the MRI model.

We further examine whether OHT anomalies in the western and central North Pacific are due to Ekman advection or geostrophic advection in the two CGCMs. Figure 5 is the same as in Fig. 4 except but the regression coefficients of geostrophic advection and Ekman advection, respectively. By directly comparing Fig. 4c, d with Fig. 5, one can find how negative OHT anomalies in relation to the positive PDO phase are associated with Ekman advection or geostrophic advection anomalies. In the MRI model, strong negative OHT anomalies in the central North Pacific are mainly due to Ekman advection. In contrast, the negative OHT anomalies in the western North Pacific can be explained by both Ekman advection and geostrophic advection. In the MIROC model, on the other hand, the negative OHT anomalies in the western North Pacific is mainly due to Ekman advection. However, those in the central North Pacific are attributed to both Ekman advection and geostrophic advection. These results indicate that the local effect of OHT due to Ekman advection and geostrophic advection in the two CGCMs, which is associated with the PDO, is different in the western and central North Pacific, respectively. Such dependency might be associated with the difference of local mean SST gradients and/or prevailing winds in the two CGCMs.
In order to examine how the PDO is affected by variation of OHT in details, we calculate temporal variations of OHT anomalies due to Ekman advection and geostrophic advection in the two CGCM together with the PDO index and their relationship is shown in Table 3. It is found that the correlation coefficients between the PDO index and OHT anomalies due to Ekman advection and geostrophic advection are statistically significant in the western North Pacific in the MRI model. However, the OHT anomalies due to Ekman advection are highly correlated with the PDO index in the central North Pacific in the MRI model. On the other hand, the OHT anomalies due to Ekman advection are correlated with the PDO index in the western and central North Pacific in the MIROC model, whereas difference in correlation with the PDO index between OHT anomalies due to Ekman advection and geostrophic advection is not large in the central North Pacific. The results in Table 3 are largely consistent with Fig. 5, that is, the region where the OHT anomalies due to Ekman advection and geostrophic advection act to change the SST associated with the PDO is different in the MRI and MIROC models, respectively.

Larger change of OHT for a given change in the PDO index (Fig. 4c, d) contributes to induce the SST changes more strongly in the MRI model. Changes in OHT for one standard deviation of the PDO index are 187.5 and $138.7^{\circ} \mathrm{Cm}$ in the western North Pacific in the MRI model and the MIROC model, respectively. In addition, those in the central North Pacific are 286.1 and $113.5^{\circ} \mathrm{Cm}$ in the two models, respectively. Therefore, a stronger PDO appears in the MRI model compared to the MIROC model, which is mainly attributed to the large change of OHT due to Ekman advection (Fig. 5; Table 3) for a given change in the PDO index in the central North Pacific.

Overall, our analyses of the MRI and MIROC models suggest that the PDO is stronger when the contribution of 
(a) MRI

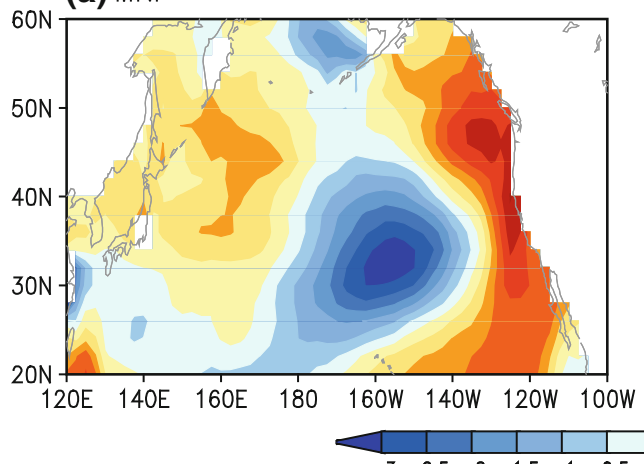

(b) MIROC

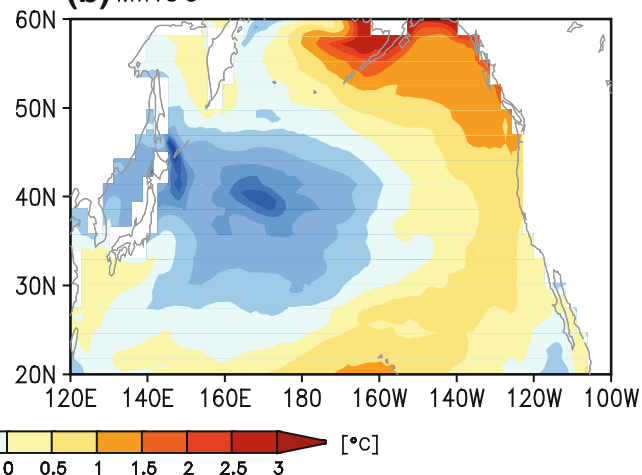

Fig. 3 Regression coefficients of the North Pacific winter mean SSTAs with the normalized NINO3.4 index in the two CGCMs. The values mean changes in SSTAs for one standard deviation of each NINO3.4 SST index

(a) SHF: MRI
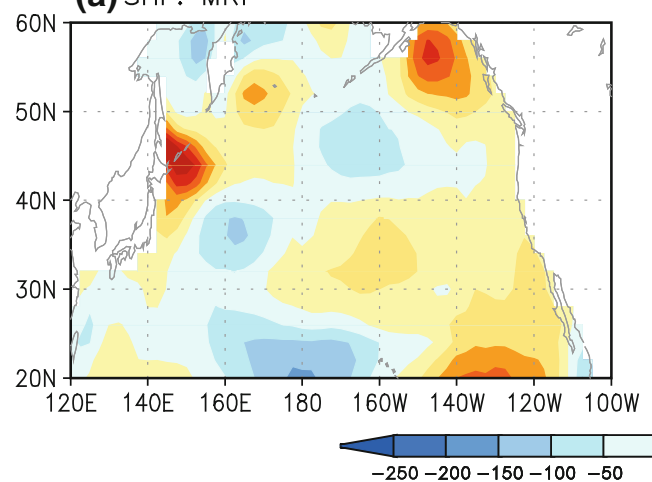

(c) OHT: MRI

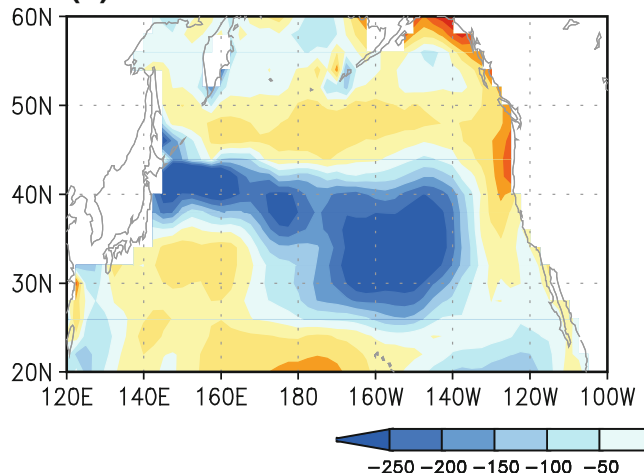

(b) MIROC

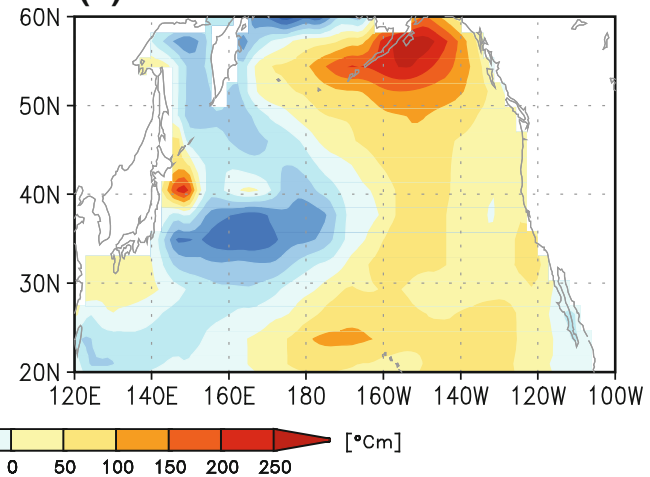

(d) MIROC

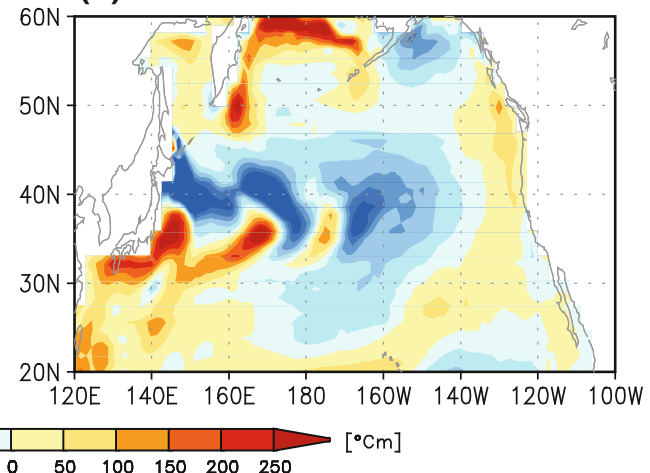

Fig. 4 Regression coefficients of $\mathbf{a}, \mathbf{b}$ SHF and $\mathbf{c}$, d OHT anomalies with the PDO index in the two CGCMs. The values mean changes in corresponding variables for one standard deviation of each PDO index

OHT to the heat budget is larger. The question arising from this result is whether this reflects the general characteristic of CGCMs. In order to examine its generality, a relationship between the strength of PDO and IOHTI in nine CGCMs in the western and central North Pacific, respectively, is shown in Fig. 6. Here, the strength of PDO for the GFDL and ECHO models is calculated by the 2nd EOF, because it exhibits typical spatial features similar to the
PDO, as mentioned in Lapp et al. (2011). It shows the tendency that the strength of PDO increases with $|\mathrm{OHT}|$, with the correlation coefficient of 0.52 and 0.56 in the western and central North Pacific, respectively. In other words, the strength of the PDO projected by the CGCMs tends to be larger for larger contribution from OHT to heat budget of the mixed layer. This result implies that ocean heat transport in the North Pacific can play an important 
(a) ADV_G: MRI

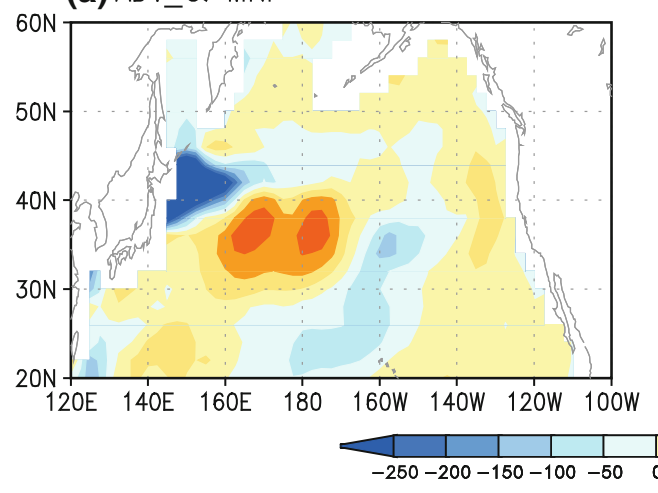

(c) ADV_E: MRI

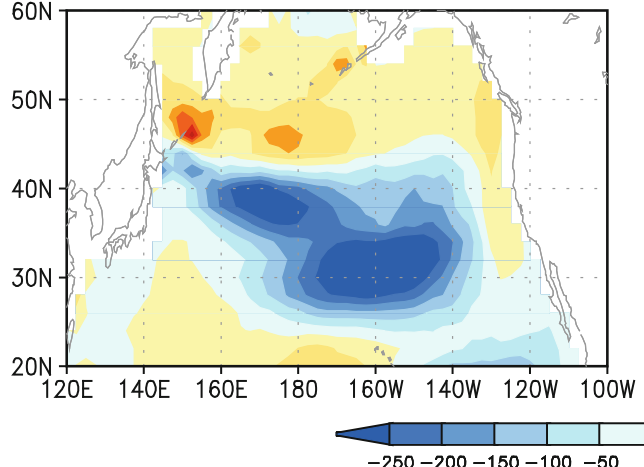

(b) MIROC

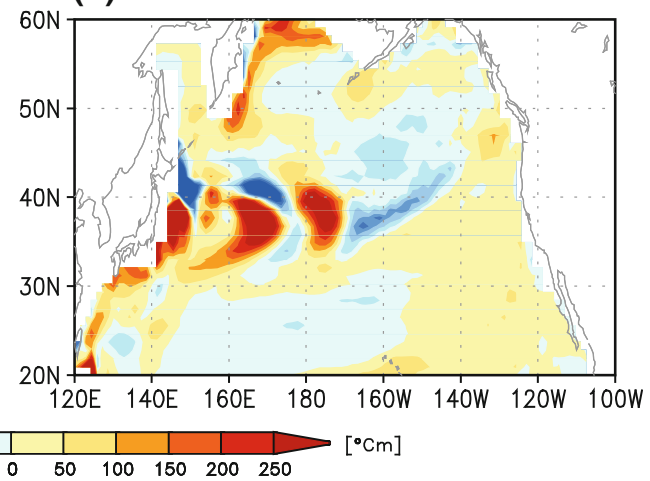

(d) MIROC

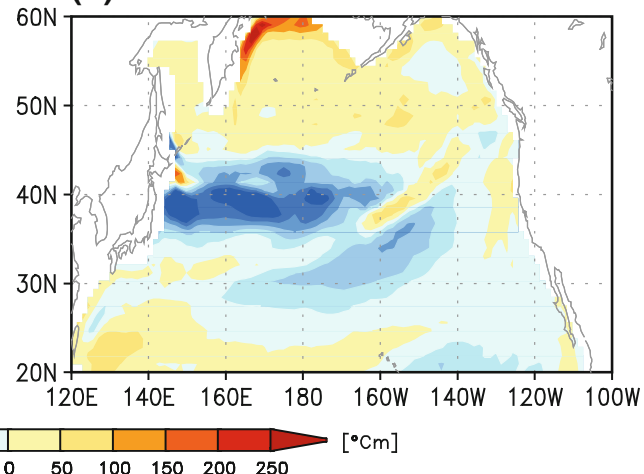

Fig. 5 The same as in Fig. 4 except but the regression coefficients of a, b geostrophic advection and $\mathbf{c}$, d Ekman advection in the two CGCMs

Table 3 Temporal correlation coefficients between the PDO index and OHT anomalies due to geostrophic advection and Ekman advection, respectively, in the WNP and CNP in the two CGCMs

\begin{tabular}{lcclll}
\hline & WNP & & & \multicolumn{2}{l}{ CNP } \\
\cline { 2 - 3 } \cline { 5 - 6 } & ADV_G & ADV_E & & ADV_G & ADV_E \\
\hline MRI & $-0.42^{*}$ & $-0.32^{*}$ & & -0.29 & $-0.67^{*}$ \\
MIROC & 0.06 & $-0.45^{*}$ & & -0.23 & $-0.37^{*}$ \\
\hline
\end{tabular}

* Statistically significant at $99 \%$ confidence level

role to determine the strength of PDO. Our further analysis indicates that OHT due to Ekman advection (geostrophic advection) in the central (western) North Pacific plays a role in the strength of PDO (Fig. 7). The contribution of OHT due to geostrophic advection in the western North Pacific is well correlated with the strength of PDO in the nine CGCMs (a correlation coefficient is 0.55 ; Fig. 7a). On the other hand, that due to Ekman advection in the central North Pacific is associated with the strength of PDO in the nine CGCMs (a correlation coefficient is 0.54; Fig. 7b). This result supports the argument that the $|\mathrm{OHT}|$ due to Ekman advection versus geostrophic advection contributes differently to the PDO in the western and central North Pacific.

\section{Summary}

In the present paper, we investigated how the properties of the mixed layer simulated by the CGCM, such as the heat budget of the mixed layer, is related to the characteristics of the projected PDO. We analyzed the spatial pattern and strength of the PDO using nine CGCM simulations in the 20C3M experiment of the CMIP3 multi-model dataset. The detailed analyses of the MRI and MIROC models reveal that the PDO is mainly affected by the variability of OHT rather than SHF in the heat budget of the mixed layer. In particular, this result that OHT plays an important role in the PDO is prominent in the MRI model which has a larger contribution of OHT to the heat budget.

We further examined the relationship between the PDO and OHT due to Ekman advection and geostrophic advection in the western and central North Pacific. This result suggests that a difference in OHT due to Ekman advection and geostrophic advection is closely related to the features of the projected PDO in the CGCMs. For example, the PDO signal in the western North Pacific is controlled by OHT anomalies due to both Ekman advection and geostrophic advection in the MRI model, whereas it is controlled by those due to Ekman advection in the MIROC model. On the other hand, a stronger PDO signal in the 
(a) WNP

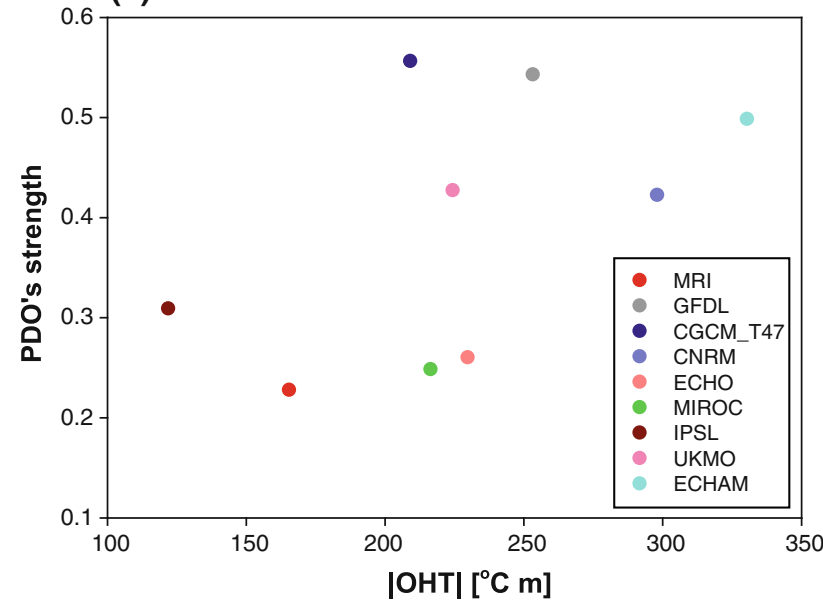

(b) CNP

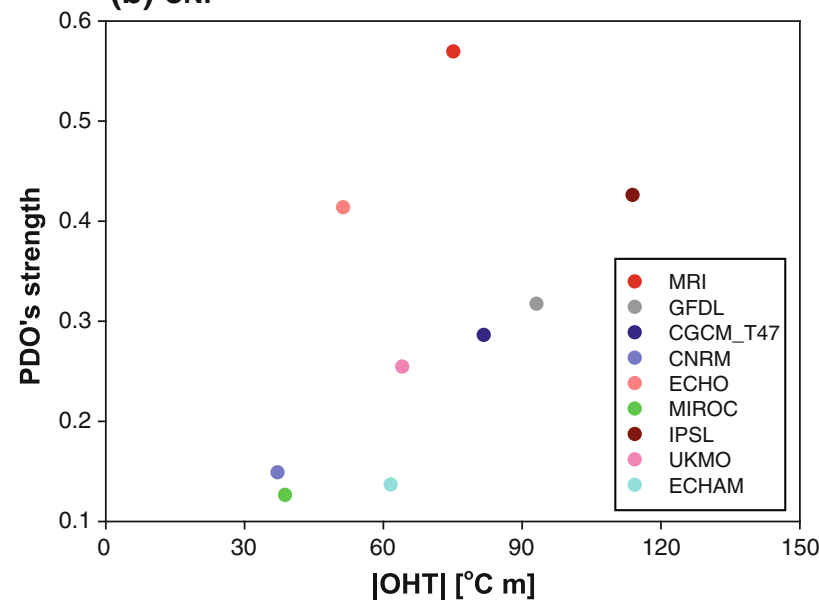

Fig. 6 Scatter diagram of $|\mathrm{OHT}|$ versus the strength of the PDO in the a WNP and $\mathbf{b}$ CNP in the nine CGCMs

central North Pacific in the MRI model is largely caused by the large change in OHT due to Ekman advection. However, the PDO signal in the central North Pacific in the MIROC model is attributed to both Ekman advection and geostrophic advection. These results indicate that the region where the OHT anomalies due to Ekman advection and geostrophic advection act to change the SST associated with the PDO is different in the two CGCMs. Furthermore, analysis of the nine CGCMs confirmed the tendency of increasing strength of PDO for larger $|\mathrm{OHT}|$ in both the western and central North Pacific. It is also found that the IOHTI due to Ekman advection versus geostrophic advection contributes differently to the PDO in the western and central North Pacific.

The present results substantiate the importance of ocean heat transport in controlling the characteristics of the PDO and also suggest that SST variability is closely related to ocean heat transport not only in the Kuroshio Extension, but also in the central North Pacific. Furthermore, they (a) WNP

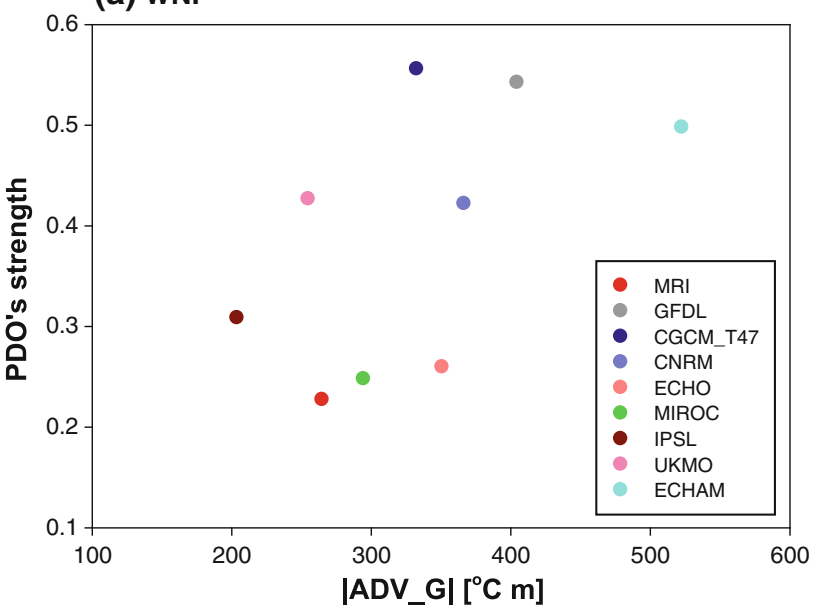

(b) CNP

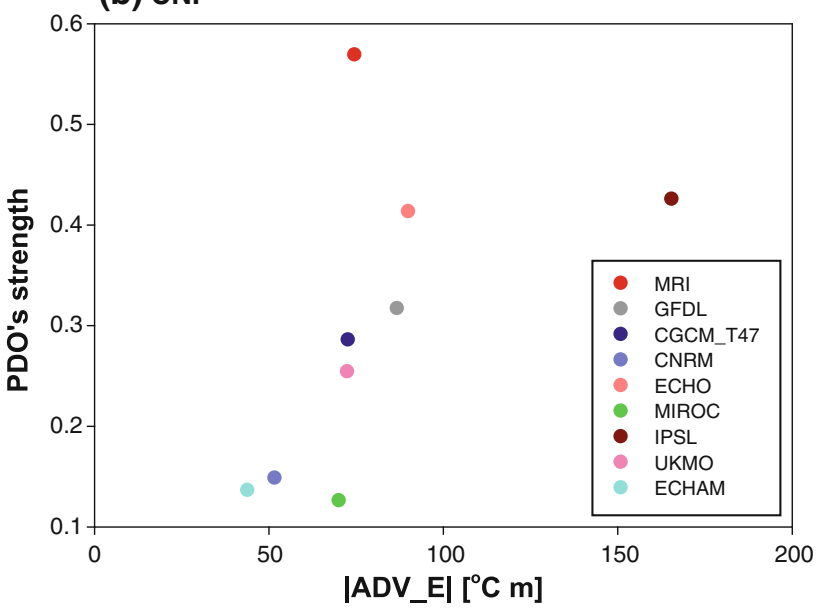

Fig. 7 Scatter diagram in the nine CGCMs: a IADV_Gl versus the strength of PDO in the WNP and $\mathbf{b} \mid \mathrm{ADV} \_$El versus the strength of PDO in the CNP

support the fact that the PDO can be modulated by local processes in the North Pacific itself, independent of the ENSO (e.g., Latif and Barnett 1996). Nevertheless, it is necessary to understand how the ocean-atmosphere coupling processes respond to variations in the ocean heat transport and how the PDO, modulated by ocean heat transport, interacts with the atmospheric teleconnections of ENSO variability.

Acknowledgments We acknowledge the international modeling groups for providing their data for analysis, the Program for Climate Model Diagnosis and Intercomparison (PCMDI) for collecting and archiving the model data, the JSC/CLIVAR Working Group on Coupled Modeling (WGCM) and their Coupled Model Intercomparison Project (CMIP) and Climate Simulation Panel for organizing the model data analysis activity, and the IPCC WG1 TSU for technical support. The IPCC Data Archive at Lawrence Livermore National Laboratory is supported by the Office of Science, US Department of Energy. This work was supported by the "National Research Foundation of Korea Grant funded by the Korean Government (MEST)" (NRF-2009-C1AAA001-2009-0093042). Y. Noh was funded by the 
Korea Meteorological Administration Research and Development Program under Grant CATER 2012-6090. B. Qiu was supported by NSF through grant OCE-0926594.

\section{References}

Salas-Melia D et al (2005) Description and validation of the CNRMCM3 global coupled model. CNRM Tech Rep 103, p 36

Barlow M, Nigam S, Berbery EH (2001) ENSO, Pacific decadal variability, and U.S. summertime precipitation, drought, and stream flow. J Clim 14:2105-2128

Capotondi A, Alexander MA (2001) Rossby waves in the tropical Pacific and their role in decadal thermocline variability. J Phys Oceanogr 31:3496-3515

Carton JA, Grodsky SA, Liu H (2008) Variability of the Oceanic mixed layer, 1960-2004. J Clim 21:1029-1047

Dawe JT, Thompson L (2007) PDO-related heat and temperature budget changes in a model of the North Pacific. J Clim 20:2092-2108

Delworth TL et al (2006) GFDLs CM2 global coupled climate models. Part I: formulation and simulation characteristics. J Clim 19:643-674

Deser C, Blackmon ML (1995) On the relationship between tropical and North Pacific sea surface temperature variations. J Clim $8: 1677-1680$

Deser C, Alexander MA, Timlin MS (1996) Upper-ocean thermal variations in the North Pacific during 1970-1991. J Clim 9:1840-1855

Enfield DB, Mestas-Nuñez AM (1999) Multiscale variability in global sea surface temperatures and their relationships with tropospheric climate pattern. J Clim 12:2719-2733

Flato GM, Boer GJ (2001) Warming asymmetry in climate change simulations. Geophys Res Lett 28:195-198

Frankignoul C (1985) Sea surface temperature anomalies, planetary waves and air-sea feedback in middle latitudes. Rev Geophys 23:357-390

Frankignoul C, Hasselmann K (1977) Stochastic climate models. Part II. Application to SST anomalies and thermocline variability. Tellus 29:289-305

Gershunov A, Barnett T (1998) Interdecadal modulation of ENSO teleconnections. Bull Am Meteor Soc 79:2715-2726

Goosse H, Fichefet T (1999) Importance of ice-ocean interactions for the global ocean circulation: a model study. J Geophys Res 104:337-355

Gordon C, Cooper C, Senior C, Banks H, Gregory J, Johns T, Mitchell J, Wood R (2000) The simulation of SST, sea ice extents and ocean heat transports in the Hadley Centre coupled model without flux adjustments. Clim Dyn 16:147-168

Hasumi H, Emori S (2004) Coupled GCM (MIROC) description. K-1 Tech Rep 1, p 34

Kang YJ, Noh Y, Yeh S-W (2010) Processes that influence the mixed layer deepening during winter in the North Pacific. J Geophys Res 115:C12004. doi:10.1029/2009JC005833

Kleeman R, Power SB (1995) A simple atmospheric model of surface heat flux for use in ocean modeling studies. J Phys Oceanogr 25:92-105

Lapp SL, St Jacques J-M, Barrow EM, Sauchyn DJ (2011) GCM projections for the Pacific Decadal Oscillation under greenhouse forcing for the early 21st century. Int J Climatol. Published online in Wiley Online Library. doi:10.1002/joc.2364

Latif M, Barnett TP (1994) Causes of decadal climate variability over the North Pacific and North America. Science 266:634-637

Latif M, Barnett TP (1996) Decadal climate variability over the North Pacific and North America: dynamics and predictability. J Clim 9:2407-2423
Legutke S, Voss R (1999) The Hamburg atmosphere-ocean coupled circulation model ECHO-G. Tech Rep 18, German Climate Computing Centre (DKRZ), p 62

Levitus S (1982) Climatological atlas of the world ocean, NOAA Prof Pap 13, p 173, US Govt Print Off, Washington, DC

Mantua NJ, Hare SR (2002) The Pacific Decadal Oscillation. J Oceanogr 58:35-44

Mantua NJ, Hare SR, Zhang Y, Wallace JM, Francis RC (1997) A Pacific interdecadal climate oscillation with impacts on salmon production. Bull Am Meteorol Soc 78:1069-1079

Marsland SJ, Haak H, Jungclaus JH, Latif M, Roeske F (2003) The Max-Planck-Institute global ocean/sea ice model with orthogonal curvilinear coordinates. Ocean Modell 5:91-127

Meehl GA, Covey C, Delworth T, Latif M, McAvaney B, Mitchell JFB, Stouffer RJ, Taylor KE (2007) The WCRP CMIP3 multimodel dataset: a new era in climate change research. Bull Am Meteorol Soc 88:1383-1394

Miller AJ, Schneider N (2000) Interdecadal climate regime dynamics in the North Pacific Ocean: theories, observations and ecosystem impacts. Prog Oceanogr 47:355-379

Miller AJ, Cayan DR, Barnett TP, Graham NE, Oberhuber JM (1994a) Interdecadal variability of the Pacific Ocean: model response to observed heat flux and wind stress anomalies. Clim Dyn 9:287-302

Miller AJ, Cayan DR, Barnett TP, Graham NE, Oberhuber JM (1994b) The 1976-77 climate shift of the Pacific Ocean. Oceanography 7:21-26

Minobe S (1997) A 50-70 year climatic oscillation over the North Pacific and North America. Geophys Res Lett 24:683-686

Monterey G, Levitus S (1997) Seasonal variability of mixed layer depth for the world ocean, NOAA Atlas NESDIS 14, Natl Oceanic and Atmos Admin, Silver Spring, MD, p 5

Nakamura H, Lin G, Yamagata T (1997) Decadal climate variability in the North Pacific during the recent decades. Bull Am Meteor Soc 78:2215-2225

Pavia EG, Graef F, Reyes J (2006) PDO-ENSO effects in the climate of Mexico. J Clim 19:6433-6438

Pierce DW, Barnett TP, Schneider N, Saravanan R, Dommenget D, Latif M (2001) The role of ocean dynamics in producing decadal climate variability in the North Pacific. Clim Dyn 18:51-70

Qiu B, Chen S (2006) Decadal variability in the formation of the North Pacific subtropical mode water: oceanic versus atmospheric control. J Phys Oceanogr 36:1365-1380

Qiu B, Schneider N, Chen S (2007) Coupled decadal variability in the North Pacific: an observationally constrained idealized model. J Clim 20:3602-3620

Schneider N, Cornuelle BD (2005) The forcing of the Pacific Decadal Oscillation. J Clim 18:4355-4373

Tomita T, Nonaka M (2006) Upper-ocean mixed layer and wintertime sea surface temperature anomalies in the North Pacific. J Clim 19:300-307

Tomita T, Xie S-P, Nonaka M (2002) Estimates of surface and subsurface forcing for decadal sea surface temperature variability in the mid-latitude North Pacific. J Meteor Soc Jpn 80:1289-1300

Trenberth KE (1990) Recent observed interdecadal climate changes in the Northern Hemisphere. Bull Am Meteorol Soc 71:988-993

Wu L, Liu Z, Gallimore R, Jacob R, Lee D, Zhong Y (2003) A coupled modelling study of Pacific decadal variability: the tropical mode and the North Pacific Mode. J Clim 16:1101-1120

Yang H, Liu Z, Wang H (2004) Influences of extratropical thermal and wind forcings on equatorial thermocline in an ocean GCM. J Phys Oceanogr 24:174-187

Yim BY, Noh Y, Yeh S-W (2012) Role of the ocean mixed layer processes in the response of the North Pacific winter SST and 
MLD to global warming in CGCMs. Clim Dyn 38(5-6):11811190. doi:10.1007/s00382-011-1120-3

Yoon J, Yeh S-W (2010) Influence of the Pacific Decadal Oscillation on the relationship between El Niño and the northeast Asian summer monsoon. J Clim 23:4525-4537

Yu B, Boer GJ (2004) The role of the western Pacific in decadal variability. Geophys Res Lett 31:L02204. doi:10.1029/2003GL 018471

Yukimoto S et al (2001) The new meteorological research institute coupled GCM (MRI-CGCM2). Model climate and variability. Pap Meteor Geophy 51:47-88
Zhang Y-L, Yu Y-Q (2011) Analysis of decadal climate variability in the tropical Pacific by coupled GCM. Atmos Oceanic Sci Lett 4:204-208

Zhang Y, Wallace JM, Iwasaka N (1996) Is climate variability over the North Pacific a linear response to ENSO? J Clim 9:1468-1478

Zhang Y, Wallace JM, Battisti DS (1997) ENSO-like interdecadal variability: 1900-1993. J Clim 10:1004-1020 